\title{
Os Sistemas de Recomendação, Arquitetura da Informação e a Encontrabilidade da Informação
}

\author{
Recommendation Systems, Information \\ Architecture, and Findability
}

\author{
Edgar Bisset ALVAREZ1 \\ Allan Lincoln Rodrigues SIRIANI ${ }^{1}$ \\ Silvana Aparecida Borsetti Gregorio VIDOTTI² \\ Angela Maria Grossi de CARVALHO3
}

\section{Resumo}

O trabalho aborda brevemente os conceitos de Arquitetura da Informação, Encontrabilidade da Informação e Sistemas de Recomendação. Seu objetivo é demostrar como a utilização dos Sistemas de Recomendação nos projetos de Arquitetura da Informação de ambientes informacionais digitais podem auxiliar os sistemas de informação no oferecimento dos dados pertinentes aos usuários que neles interatuam, possibilitando, assim, a descoberta da Encontrabilidade da Informação pelos usuários. Para tanto, realizou-se uma análise bibliográfica a qual possibilitou a contextualização dos termos tratados neste trabalho e, também, um estudo dos sites (Amazon.com) para conhecer o comportamento do Sistema de Recomendação do mesmo e como podem aumentar o processo de Encontrabilidade da Informação nos ambientes informacionais digitais. Concluiu-se que a quantidade de informação disponível na web na atualidade dificulta a encontrabilidade dos dados disponibilizados por parte dos usuários, o que impossibilita aos sistemas entregar a informação adequada no momento exato. Por isso a utilização dos Sistemas de Recomendação nos projetos de Arquitetura da Informação é considerada uma variante para que os sistemas de informação ofereçam os dados facilitando a apropriação dos mesmos pelos usuários.

Palavras-chave: Ambiente informacional. Arquitetura da informação. Encontrabilidade da informação. Informação e tecnologia. Sistemas de recomendação.

\begin{abstract}
The present study discusses briefly the concepts of Information Architecture, Information Findability, and Recommendation Systems. It aims to demonstrate how the use of Recommendation Systems in Information Architecture of digital environments can help Information systems by providing users with relevant information enabling information discovery and findability. A literature review was conducted, allowing the contextualization of the terms used in this study. The Amazon.com website was analyzed to evaluate its Recommendation Systems and understand how they can improve Information Findability in digital information environments. It was concluded that the amount of available information on the World Wide Web today hinders the Findability of Information provided by users making it difficult for systems to provide the right information at the right time. Therefore, the use of Recommendation Systems in Information Architecture projects is considered an effective approach to information systems since it facilitates the appropriation of information by users.

Keywords: Information environment. Information architecture. Information findability. Information and technology. Recommendation systems.

\footnotetext{
1 Universidade Estadual Paulista, Faculdade de Filosofia e Ciências, Programa de Pós-Graduação em Ciência da Informação. Av. Hygino Muzzi Filho, 737, Mirante, 17525-000, Marília, SP, Brasil. Correspondência para/Correspondence to: E.B. ALVAREZ.E-mail:<ebicet@gmail.com>.

2 Universidade Estadual Paulista, Faculdade de Filosofia e Ciências, Departamento de Ciência da Informação. Marília, SP, Brasil.

3 Universidade Estadual Paulista Júlio de Mesquita Filho, Faculdade de Arquitetura, Arte e Comunicação, Departamento de Comunicação Social. Bauru, SP, Brasil.

Recebido em 27/4/2015, reapresentado em 21/1/2016 e aceito para publicação em 22/2/2016.
} 


\section{Introdução}

Com o desenvolvimento das Tecnologias da Informação e Comunicação (TIC) nas últimas décadas, a onda de conteúdo disponibilizado na web alcança um tamanho nunca antes imaginado. Cada vez mais as pessoas participam na criação, gerenciamento e compartilhamento de conteúdo, fato este que se intensificou com o desenvolvimento das redes sociais, dos avanços na tecnologia móvel, com a criação de aplicativos para a interação entre os usuários e com os muitos ambientes digitais disponíveis na rede.

Diante disso, ficou clara a necessidade de melhoria dos sistemas de informação no que diz respeito a sua estrutura informacional, já que o mesmo organiza e oferece aos seus usuários a informação pertinente para cada momento. Essa necessidade tornou-se uma prioridade, fazendo com que seja cada vez mais importante trabalhar em projetos de Arquitetura da Informação os quais promovam a criação de ambientes informacionais mais focados em melhorar a experiência dos usuários finais. Morville (2005) disserta sobre esse fenômeno quando se refere aos processos de Encontrabilidade da Informação em ambientes informacionais, colocando a Arquitetura da Informação, como o processo mediador entre os ambientes informacionais e os interesses dos usuários.

Tendo em conta a enorme e crescente quantidade de ambientes informacionais de complexidade cada vez mais desafiadora, tanto com relação a abordagem teórica quanto prática, e a grande variedade de enfoques sobre a abrangência da Arquitetura da Informação, fez-se necessária a análise de algumas das teorias que se apresentam como esclarecedoras no que diz respeito aos diferentes caminhos abordados na construção prática desse campo. A literatura traz autores como Rosenfeld e Morville (1998; 2006), Brown (2003), Van Dijck (2003), Batley (2007), McCool (2007) e Wodtke e Govella (2009), os quais propõem conceitos de Arquitetura da Informação, porém com enfoque prático. Cada um, baseado em suas próprias experiências, oferece ferramentas, técnicas e conceitos que sugerem soluções a problemas pontuais na construção e criação de ambientes digitais. Esses autores destacam em suas publicações a necessidade de projetos de Arquitetura da Informação que acompanhem a evolução e variedade de mídias e tecnologias, as quais se desenvolvem a um ritmo acelerado, com o objetivo de criar ambientes de informação agradáveis, usáveis, simples e valiosos.

Nos dias atuais, no momento de projetar a Arquitetura da Informação de um ambiente digital é importante levar em consideração a relação que se estabelece entre "[...] ambientes/sistemas de informação e sujeitos informacionais" (Vechiato, 2013, p.18). Nesse sentido, analisando Morville (2005), Vechiato (2013, p.18) coloca a encontrabilidade da informação como elemento que relaciona "[...] a efetividade do funcionamento dos ambientes/sistemas de informação e as características e experiências dos sujeitos".

Na premissa de ofertar uma melhor experiência de navegação em um ambiente digital, as tecnologias de recomendação foram implementadas em sites de e-commerce visando aumentar o oferecimento de informações dos produtos comercializados pelas empresas a seus usuários. Diz-se que o My Yahoo foi o primeiro website a utilizar os Sistemas de Recomendação em grande escala em 1996. Esse tipo de sistema é amplamente utilizado na atualidade na área do e-commerce, auxiliando, principalmente, no aumento dos lucros das empresas, na medida em que encontra os produtos mais adequados para seus clientes e os oferece em forma de recomendação.

Existem autores que abordam o uso dos sistemas de recomendação em ambientes digitais vinculados a unidades de informação (bibliotecas, arquivos, centros de informação, entre outros) levantando a pergunta: quais seriam as vantagens da introdução desses sistemas na área das Ciências da Informação? Assim, com a apresentação e análise das definições de Arquitetura da Informação, Encontrabilidade da Informação e Sistemas de Recomendação, buscou-se apresentar como a utilização dos Sistemas de Recomendação nos projetos de Arquitetura da Informação de ambientes informacionais digitais podem auxiliar os sistemas de informação no oferecimento dos dados pertinentes aos usuários que neles interatuam, possibilitando assim a descoberta da encontrabilidade da informação.

\section{Procedimentos metodológicos}

Neste trabalho utilizou-se o método de análise bibliográfico, o qual possibilitou uma breve aproximação 
dos conceitos de Arquitetura da Informação, Encontrabilidade da Informação e Sistemas de Recomendação. Dessa maneira, foi possível estudar o contexto teórico que permite colocar em debate quais seriam as possíveis vantagens da utilização de Sistemas de Recomendação nos projetos de Arquitetura da Informação, aumentando, portanto, os processos de Encontrabilidade da Informação nos ambientes informacionais.

Como parte desta pesquisa de corte qualitativo e a fim de alcançar o objetivo traçado, fez-se uma análise exploratória do site Amazon.com considerado pela literatura entre os mais completos no que se refere ao uso das estratégias de recomendação. Desse modo, tomou-se parte de forma ativa, e na medida em que os ambientes o permitiram, dos processos, atividades e fluxos informacionais da comunidade de usuários.

Para começar a pesquisa foram criadas várias contas de usuários diretos dos sistemas. Como os ambientes eram de caráter predominantemente comercial, decidiu-se que as buscas seriam sobre alguns dos produtos comercializados no mesmo, criando, assim, uma série de movimentações as quais possibilitassem ao sistema coletar dados da experiência e recomendar determinados produtos. Buscou-se, então, saber como esse processo facilitou a encontrabilidade da informação nesse ambiente informacional. O estudo concentrou-se, principalmente, nas recomendações que os Sistemas de Recomendação dos sites ofereciam para cada operação executada, procurando conhecer até que ponto o mesmo poderia levar o usuário a novas descobertas de informações que tivessem alguma relação com as buscas realizadas.

\section{Arquitetura da Informação}

Durante muitos anos tem-se visto a web como um sistema de publicação textual rápido e sem muitas complicações técnicas, onde o usuário cria, compartilha e acessa uma quantidade imensa de informação. A aparente facilidade para criar sítios web, em união com a popularização de editores de texto, disponibilizou e generalizou a possibilidade de criar e gerenciar conteúdos na Internet.

Existiu uma época na qual, erroneamente, pressupôs-se que a existência desse colossal acúmulo de informações traria consigo um aumento nas probabilidades dos usuários encontrarem informação sobre qualquer tema na Internet sempre que procurassem. Mas, além do caos informacional no qual se converteu a web, durante muitos anos foram sendo criados ambientes informacionais digitais cada vez mais complexos, nos quais, muitas vezes, setores que incursionavam na web não levavam em consideração elementos essenciais, como a organização, usabilidade, acessibilidade e representação da informação, dificultando ainda mais a possibilidade do usuário encontrar nesse oceano de conteúdo a informação relevante às suas necessidades. No entanto, deve-se destacar que nos ambientes digitais vinculados ao comércio eletrônico esse processo foi muito mais organizado, pois percebeu-se que dessa maneira melhorava-se consideravelmente a interação e experiência do usuário final com seus produtos e, ainda, aumentavam os benefícios da empresa.

Ante a necessidade de organizar toda essa confusão, muitos autores acreditam que a possibilidade de diminuir esse problema vem da Arquitetura da Informação, cujo objetivo é a organização e estruturação das informações disponibilizadas nos websites. Ela atua sobre os ambientes digitais definindo, primeiramente, a forma de alcançar com eficácia e eficiência os objetivos a cumprir e o público alvo.

A Arquitetura da Informação refere-se ao desenho das informações: como textos, imagens e sons são apresentados na tela do computador, a classificação dessas informações em agrupamentos de acordo com os objetivos do site e das necessidades do usuário, bem como a construção de estrutura de navegação e de busca de informações, isto é, os caminhos que o usuário poderá percorrer para chegar até a informação (Straioto, 2002, p.20).

Arquitetura da Informação é um termo muito utilizado em espaços de desenvolvimento tecnológico, criação e design de sítios web. Seu surgimento é atribuído na literatura científica ao pesquisador Richard Saul Wurmam que, no ano de 1975, junto com Joel Katz, publicou o artigo titulado "Beyond Graphics: The Architecture of Information". No entanto, León (2008) apresenta estudos os quais demostram como desde anos anteriores o termo "arquitetura" vinha sendo utilizado nos contextos tecnológicos, principalmente naqueles ligados 
à área computacional. Outros autores, como Resmini e Rosati (2011), complementam essa revisão, abordando as mais recentes perspectivas teóricas e práticas da Arquitetura da Informação, a "pervasividade" e a "ubiquidade".

Em seu trabalho, León aponta que o termo "arquitetura", começou a ser utilizado no contexto computacional no ano de 1959 por Lyle R. Jonson e Frederick P. Brook, ambos pesquisadores dos laboratórios da International Business Machines (IBM). Anos mais tarde, o termo aparece no capítulo dois do livro "Planning a Computer System: Project Stretch", onde Brook (1962) descreve a arquitetura dos computadores como a arte de determinar as necessidades dos usuários nas organizações com o intuito de poder satisfazê-las o mais eficientemente possível.

Outros indícios de conceitualização desse termo encontram-se registrados na literatura técnica da IBM, onde faz-se uma distinção que coloca a arquitetura como a "estrutura conceitual e comportamento funcional" e a diferencia da "organização dos fluxos de dados e controles, o designer lógico e a implementação física" (Amdahl et al., 1964, p.22). Ainda em sua revisão, León destaca o uso do termo no contexto tecnológico pelo Grupo de Arquitetura de Máquinas do Massachusetts Institute of Technology (MIT), fundado em 1967 por Nicholas Negroponte.

Embora as conceitualizações apresentadas façam referência ao uso do termo "arquitetura" no contexto computacional, é importante lembrar que serviram de base para a aparição, em 1970, do termo "Arquitetura da Informação". Esse fato é evidenciado na obra de Pake (1985), comentado por León (2008) e por Resmini e Rosati (2011), quando discursa sobre a missão, passada para um grupo de cientistas das áreas das Ciências Naturais e da Ciência da Informação, de criar uma Arquitetura da Informação que pudesse ser aplicada aos artefatos tecnológicos desenvolvidos pela Xerox Palo Alto Research Center, empresa recém-criada e que fez grandes avanços na área de Interação Humano-Computador (IHC), destacando-se pelo aporte no projeto do primeiro computador pessoal com interface amigável.

Existem, na literatura, várias definições para o termo Arquitetura da Informação. No período dos anos 1990 foram publicados uma série de livros que até hoje são considerados clássicos na difusão dessa área como profissão e na construção de um aparato histórico-conceitual para que a mesma pudesse se estabelecer enquanto campo de conhecimento. Dentre os autores mais destacados pode-se mencionar Cook (1996), Wurman (1996), Nielsen (1998), Rosenfeld e Morville (1998; 2006) e Kahn e Lenk (2001). Estes últimos afirmam que o termo Arquitetura da Informação refere-se à:

1. Desenho estrutural de um espaço de informação para facilitar as tarefas de acabado e acesso intuitivo aos conteúdos;

2. Combinação da organização, etiquetado e os esquemas de navegação no interior de um sistema de informação;

3. A arte e ciência de estruturar e classificar websites e intranets para ajudar aos usuários no processo de encontrar e gerenciar a sua informação;

4. Disciplina emergente e uma comunidade prática focada em trazer os princípios do desenho e a arquitetura aos espaços digitais (Rosenfeld \& Morville, 2006, p.4) (tradução nossa) ${ }^{4}$.

Esses autores também destacam que a Arquitetura da Informação abrange processos, como: clarificar a missão e visão do sítio, equilibrando as necessidades do patrocinador e as da audiência; determinar o conteúdo e funcionalidade que o sítio vai ter; especificar como os usuários vão encontrar a informação ao definir sua organização, navegação, rotulagem e sistemas de busca; e representar como o sítio vai se acomodar às mudanças e crescimento no tempo (Rosenfeld \& Morville, 2006).

Macedo (2005, p.132) traz outra definição do termo Arquitetura da Informação como sendo "[...] uma metodologia de desenho que se aplica a qualquer ambiente informacional, sendo este compreendido

\footnotetext{
4 "1. The structural design of shared information environments;

2. The combination of organization, labeling, search, and navigation systems within web sites and intranets,

3. The art and science of shaping information products and experiences to support usability and findability;

4. An emerging discipline and community of practice focused on bringing principles of design and architecture to the digital landscape".
} 
como um espaço localizado em um contexto; constituído por conteúdos em fluxo; que serve a uma comunidade de usuários". Além disso, segundo Rosenfeld e Morville (2006, p.43), a Arquitetura da Informação está formada por quatro grandes sistemas interdependentes, o"sistema de organização, sistema de rotulagem, sistema de navegação e sistema de busca" (tradução nossa) ${ }^{\mathbf{5}}$, igualmente Vidotti et al. (2008, p.182) detalha e amplia os elementos e processos essenciais que se destacam nos quatros sistemas apresentados por Rosenfeld e Morville (2006):

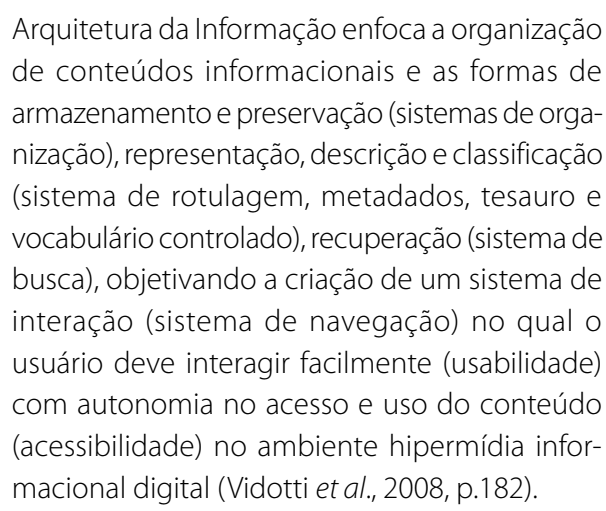

Nas definições antes vistas, percebe-se como cada uma destaca o estabelecimento de uma interligação entre contexto, conteúdo e usuário como parte essencial para o desenvolvimento de todo o projeto da Arquitetura da Informação, muito embora Silva e Dias (2008) esclareçam que cada um desses elementos, assim como a estreita relação que se estabelece entre eles, comportam-se de forma única para cada projeto.

Cada um desses sistemas tem como função fazer com que o usuário final utilize o mínimo esforço possível na busca pela informação de seu interesse. No entanto, segundo Morville e Sullenger (2010) "em nível de sistema ou ambiente de informação, a encontrabilidade da informação está diretamente relacionada à navegação e à busca" (Vechiato, 2013, p.118).

\section{Encontrabilidade da Informação}

O processo de encontrar ou achar alguma informação está indissoluvelmente ligado à uma forte necessidade do indivíduo (declarada ou não) de satisfazer uma lacuna de conhecimento nele criada como resposta à uma situação em um determinado contexto. Na atualidade, a grande quantidade de dados disponível na web, produto do considerável aumento nos avanços tecnológicos e comunicacionais, assim como da ampla participação dos usuários, tanto na produção quanto na criação de conteúdo online, constitui um dos principais problemas na hora de projetar a Arquitetura da Informação de um website. Vechiato e Vidotti (2009) entendem que a Arquitetura da Informação agrega estudos como usabilidade, acessibilidade e comportamento informacional, os quais, quando aplicados em conjunto, possuem subsídios teóricos e práticos adequados para o projeto e para a construção de ambientes informacionais digitais.

Encontrabilidade da Informação é um termo introduzido por Morville (2005, p.4) para referir-se à capacidade de uma informação ser encontrada em um ambiente informacional, considerando a qualidade (ser localizável ou navegável), o grau com o qual um determinado objeto é descoberto ou localizado nesse ambiente e, por último, o grau no qual esses sistemas suportam a navegação e a recuperação. Porém, segundo Vechiato (2013, p.169), a Encontrabilidade da Informação é um "elemento que se situa entre as funcionalidades de um ambiente informacional tradicional, digital ou híbrido e as características dos sujeitos", estando relacionada a processos que compõem o fluxo infocomunicacional e que possibilitam o encontro da informação adequada às necessidades dos usuários em diferentes situações de busca.

A definição de ambos os autores para Encontrabilidade da Informação deixa claro que a mesma vai depender do estado psicossocial do indivíduo no momento da busca, bem como da qualidade dos sistemas de busca e navegação disponíveis. Porém, não é sempre que os mecanismos e técnicas de buscas vão auxiliar o usuário a encontrar o dado, pois, muitas vezes, ele próprio não tem conhecimento de todas as suas necessidades de informação. Além disso, durante a navegação podem ser descobertas coisas das quais o usuário nem sabia que precisava, dando início a um novo comportamento nos processos de busca e navegação.

\footnotetext{
5 "Organization systems; Navigation systems; Search systems; Labeling systems" (Rosenfeld \& Morville, 2006, p.73).
} 
E é por isso que se recomenda adotar estratégias nos projetos de Arquitetura da Informação focadas em promover a descoberta de informação. Uma delas é a criação de"[...] affordances (pistas) com vistas à exploração de conteúdos que os usuários não sabem que existem" (Spagnolo et al., 2010). Neste sentido, durante as últimas décadas, os desenvolvedores de sistemas de informação têm apostado na inclusão dos chamados Sistemas de Recomendação, utilizados para sugerir aqueles produto e serviços que o usuário não está procurando de início, mas que podem estar associados aos seus interesses, facilitando, assim, a encontrabilidade da informação.

\section{Sistemas de Recomendação}

Nos últimos anos, as pessoas têm sido inundadas por uma grande onda de informação e de dados referentes a todas as áreas da vida em sociedade. Dessa forma, o usuário depara-se com um gigantesco oceano de informação digital, que nem sempre está bem organizado ou representado. Além disso, os processos de busca e recuperação da informação são cada vez mais complicados e nem sempre a pessoa está preparada ou tem a experiência necessária para elaborar as estratégias de busca que o levem ao encontro da informação que precisa. Uma das ferramentas atualmente mais usada para diminuir esse problema é a utilização dos Sistemas de Recomendação nos diferentes ambientes ou sistemas de informação, os quais facilitam o encontro de dados durante os processos de busca e navegação, oferecendo aos usuários indicações daqueles produtos e serviços que poderiam estar associados ou relacionados às suas necessidades.

Segundo Resnick eVarian (1997, p.57) os Sistemas de Recomendação são:

[...] sistemas que utilizam as opiniões de uma comunidade de usuários para auxiliar indivíduos desta mesma comunidade a identificarem conteúdos de interesse em um conjunto de opções que poderiam caracterizar uma sobrecarga.

No entanto, para o adequado funcionamento desses sistemas, os mesmos devem dispor de um amplo conhecimento sobre os usuários com os quais interatuam, saber sobre as suas preferências, gostos e ne- cessidades. Para tanto, os elementos essenciais são a coleta, o processamento e o armazenamento dos dados dos usuários, que possibilitam a identificação dos mesmos ao mesmo tempo que facilitam o oferecimento das informações sobre aqueles produtos que tem relação com seus perfis.

A coleta dos dados dos usuários pode acontecer de forma explícita, comumente chamada de customização, onde a pessoa indica quais são seus interesses criando um perfil sobre seus gostos e prioridades; ou de forma implícita, quando o sistema sugere os gostos e preferências dos usuários através de suas ações. No caso da segunda opção, cabe discutir até que ponto a prática seria considerada ética ou, quem sabe, até mesmo legal. No entanto, esse é um assunto que vai além do objetivo do presente trabalho que é demostrar como esses dados podem ser utilizados para gerar novas ofertas de informação.

A identificação dos usuários se produz de duas formas:

Identificação no servidor: solicitam-se aos usuários através de formulário, algumas informações pessoais, assim login e senha, armazenando em uma base de dados, permitindo assim ao sistema a identificação do usuário uma vez ele se identifique no acesso.

Identificação no cliente: baseia-se na identificação através de cookies de aquelas máquinas que acessam ao sistema, presumindo-se que estas são utilizadas pelo mesmo usuário, elemento este que não é muito confiável, já que, se o computador estivesse em um estabelecimento onde o uso deles fosse compartilhado por vários usuários, o sistema não teria como identificar, que usuário está fazendo uso do computador nesse momento, sendo impossível traçar um perfil do mesmo (Reategui \& Cazella, 2005, p.308).

Uma vez coletadas as informações sobre os usuários e os produtos, outro problema se apresenta: definir quais produtos indicar para cada usuário. Isso faz com que os sistemas de informação apresentem grande dificuldade na entrega dos dados buscados em cada momento, tornando imprescindível realizar o processo de filtragem da informação como elemento primordial na identificação de padrões de comportamento e de personalização do relacionamento sistema-usuários. 
Segundo Belvin e Croft (1992, p.27) "filtragem de informação é o nome utilizado para descrever uma variedade de processos que envolvem a entrega de informação para as pessoas que realmente necessitam delas" (tradução nossa) 6 . São três as técnicas de filtragem mais usadas:

Filtragem baseada em conteúdo: realiza uma seleção baseada na análise de conteúdo dos itens e no perfil do usuário.

Filtragem colaborativa: a essência está na troca de experiências entre as pessoas que possuem interesses comuns.

Filtragem híbrida: procura combinar os pontos fortes da filtragem colaborativa e filtragem baseada em conteúdo visando criar um sistema que possa melhor atender as necessidades do usuário (Reategui \& Cazella, 2005, p.319).

No entanto, existe uma quarta técnica de filtragem baseada no conhecimento que o sistema tem sobre as características do usuário, dos produtos e o conhecimento do ambiente, apresentando assim recomendações com raciocínios semânticos de forma flexível e contextualizada. Essa técnica permite ao Sistema de Recomendação aprender dos perfis dos usuários para uma futura personalização dos resultados, assim como a apresentação de recomendações baseadas em inferências, fato que alivia o arranque do sistema desde o zero ou na dispersão dos dados.

Uma vez filtrada a informação, é o momento de oferecer a cada usuário aquelas recomendações adequadas ao perfil individual. São várias as estratégias de recomendação utilizadas pelos Sistemas de Recomendação:

Listas de recomendação: consiste em manter listas de itens organizados por tipos de interesses.

Avaliações de usuários: consiste na recomendação baseada na avaliação dos produtos feita pelos usuários.

Suas Recomendações: oferecido em uma seção inteiramente dedicada a sugestões feitas especificamente para o usuário. Dois tipos de recomendação são possíveis nestas seções: aquelas feitas a partir de preferências implícitas ou explícitas.
Usuários que se interessaram por $X$ também se interessaram por Y: tipo de recomendação é obtido através de técnicas capazes de encontrar em uma base de dados associações entre itens avaliados por usuários.

Associação por conteúdo: recomendações feitas com base no analise do conteúdo de determinado item (Reategui \& Cazella, 2005, p.310).

Muito embora essas estratégias tenham sido de grande ajuda, tanto na entrega da informação pelos sistemas quanto na descoberta de novos dados pelos usuários, ainda existem grandes lacunas no que se refere às recomendações sugeridas. Isso acontece porque, geralmente, são apresentadas recomendações a cada usuário baseadas em seu histórico de navegação ou de compras as quais não são mais úteis caso este vier a realizar uma busca para suprir as necessidades de outra pessoa (como, por exemplo, um presente de aniversário).

No entanto, Souza (2012) em uma releitura de Iskold (2007) assegura que esse problema é realmente difícil de ser resolvido, apesar dos grandes esforços que vêm se realizando para solucioná-lo. Assim, existem quatro abordagens principais para a construção de recomendações:

- Recomendação personalizada: recomenda coisas baseada no histórico de comportamento.

- Recomendação social: recomenda coisas baseada no histórico de comportamento de usuários parecidos.

- Recomendação de item: recomenda coisas baseada na própria coisa.

Uma combinação das três abordagens acima.

Como hodiernamente os Sistemas de Recomendação constituem peça fundamental no e-commerce e em sua relação com os usuários, os empresários e donos dos grandes sites de vendas têm investido muito dinheiro no desenvolvimento desse tipo de sistema com a finalidade de atrair, cada vez mais, aquelas pessoas indecisas através das recomendações, convencendo-as a realizar transações. Nesse sentido, existem alguns exemplos de Sistemas de Recomendação que estão dando ótimos resultados, como é o caso do Amazon.com, del.icio.us e Pandora. A grande diferença dentre os outros varejistas 
é que esses sites têm melhorado muito a sua infraestrutura e acumulado uma grande quantidade de dados de seus usuários, o que Ihes permite dar uma atenção mais personalizada e oferecer recomendações cada vez mais convincentes, facilitando, assim, a descoberta e o encontro de novas informações. Dessa maneira, na sessão a seguir faz-se uma análise do funcionamento do Sistema de Recomendação no site Amazon.com tendo como objetivo correlacionar os sistemas de recomendação expostos na interface do usuário com os conceitos da encontrabilidade da informação e da Arquitetura da Informação.

\section{Resultados e Discussão}

O estudo parte da busca realizada no site Amazon.com utilizando como palavra-chave o termo shoes (do inglês, sapatos), o que desencadeia uma sequência de ações dos sistemas de recomendação do site as quais levam o usuário à descoberta de outros produtos presumivelmente importantes para ele. Na Figura 1, observa-se como o sistema reconheceu que o usuário com o qual estava interagindo era do gênero masculino (possivelmente através dos dados inseridos no momento do cadastro), pois os primeiros itens exibidos nos resultados da busca eram de calçados masculinos.
Para gerar informações nos Sistemas de Recomendação, foi escolhido navegar apenas pela sessão de sapatos masculinos. Assim, realizou-se a navegação por oito itens, fato que gerou dados para o Sistema de Recomendação sobre os interesses do usuário. A caixa no layout das páginas, chamada "Frequentemente comprados juntos", gera uma recomendação baseada em informações derivadas de compras de um determinado item no passado, ou seja, o cliente A compra o item $X$ e o item $Y$ no mesmo pedido e, nesse momento, é feito um relacionamento entre ambos os produtos; porém, quando um cliente B seleciona o item X o sistema de recomendação sugere na caixa "Frequentemente comprados juntos" o item $Y$, dando a possibilidade do usuário escolher outra opção de compra.

Mostrando os resultados da busca em todos os departamentos. Resultado relacionados: calçados marcax.

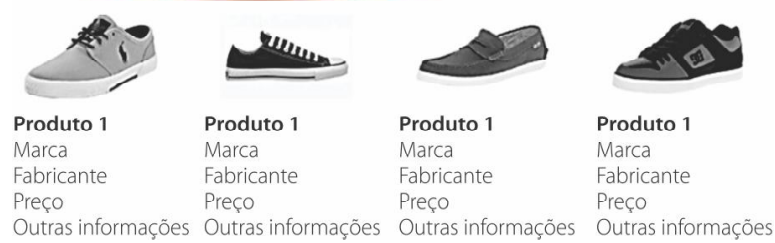

Figura 1. Como são apresentados os itens após uma busca. Fonte: Elaborada pelos autores (2014).

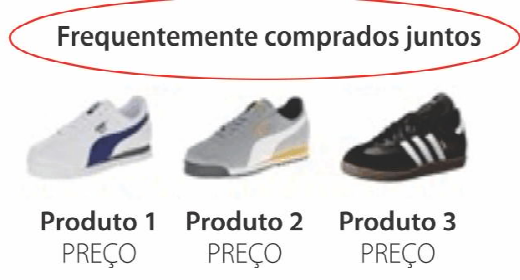

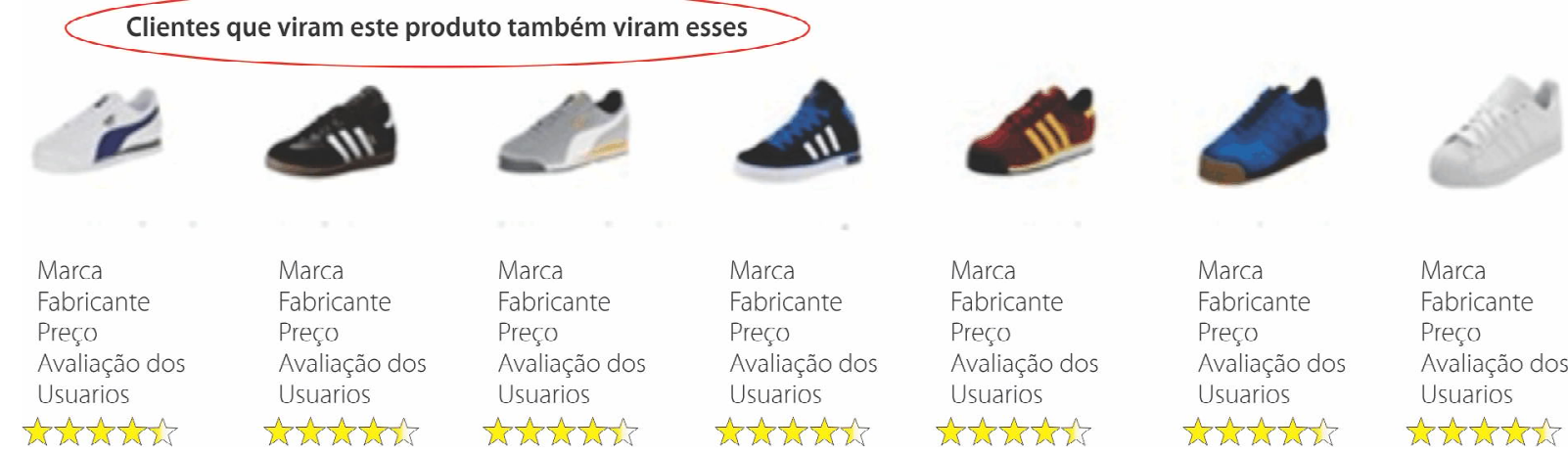

Figura 2. Recomendações baseadas no histórico de compras de outros usuários e em associações do histórico de visualização de itens. Fonte: Elaborada pelos autores (2014). 
Estão presentes no layout da página de detalhes do produto outras caixas como a"Clientes que viram este produto também viram esses". Nela foi observada a associação de outros itens para recomendação baseados no histórico de navegação de outros usuários. Nesse caso, são recomendadas outras opções dos itens $X$ e Y. Na Figura 2 apresentam-se as recomendações do Sistema de Recomendação do site, baseadas no histórico de compras de outros usuários e em associações do histórico de visualização de itens.

Outra característica encontrada foi a recomendação de produtos segundo a avaliação da reputação do item que foi gerado somada à análise dos dados obtidos a partir da avaliação dada pelos usuários que adquiriram esse item na caixa "Comentários de clientes". Isso se dá porque os comentários dos clientes auxiliam na decisão de compra do usuário, já que constrói em seu modelo cognitivo eventos os quais o auxiliam na tomada de decisão, sendo as informações de outros consumidores essenciais nesse processo.

Na busca do item correto para a efetivação da compra, o usuário pode obter informações nos comentários e neles basear sua decisão. Estes são experiências de outras pessoas as quais já adquiriam o mesmo produto. A Figura 3 apresenta um exemplo de como é feita a avaliação pelos usuários que adquiriram o mesmo produto e os comentários associados à suas experiências.

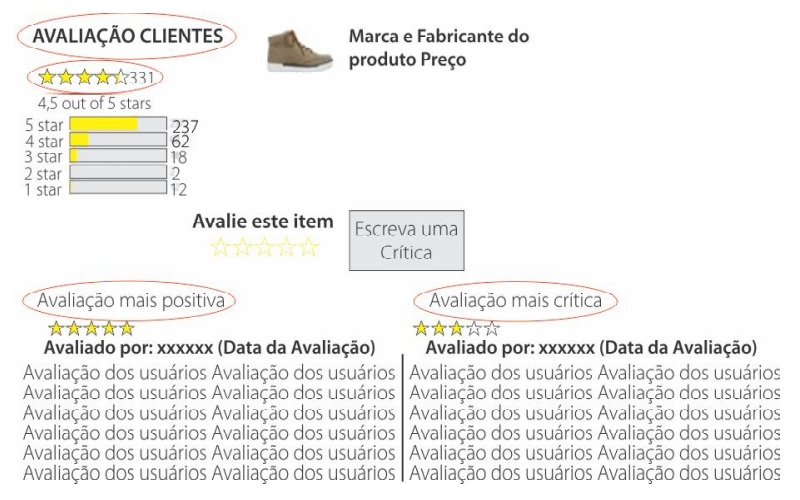

Figura 3. Avaliações e comentários dos usuários sobre os produtos.

Fonte: Elaborada pelos autores (2014).
Cliente que viram este produto também viram esses

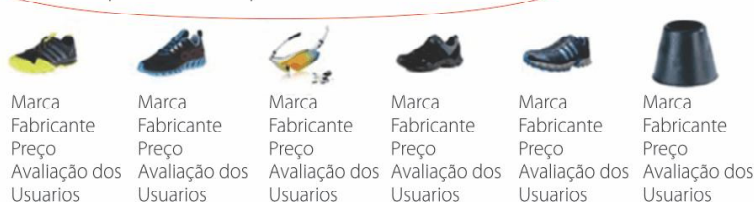

Figura 4. Recomendações baseadas nos itens comprados por outros usuários.

Fonte: Elaborada pelos autores (2014).

No Sistema de Recomendação baseado no histórico de compras, são coletados dados de compras dos usuários os quais permitem gerar recomendações indicando quais "clientes compraram o item $\mathrm{X}$ e também compraram o item Y", além de serem exibidos outros itens adquiridos pelos usuários que compraram o item $Y$. Para ilustrar a situação, o cliente A compra o item $X$; após alguns meses o mesmo usuário $A$ compra o item $Y$ e a partir daí é criada a assertiva "clientes que compraram o item X também compraram o item Y". Assim, quando um cliente $B$ visualiza o item $X$ aparece a mensagem "clientes que compraram este item também compraram" recomendando o item Y (Figura 4).

Esta caixa pode ser um objeto para promover o serendipismo, pois só está sendo gerado histórico de determinados produtos. Porém, o Sistema de Recomendação por associação sugere outros itens os quais podem promover novas descobertas relacionando diretamente novos itens ao termo de busca.

O histórico de navegação criado pelos pesquisadores deste estudo alimentou o Sistema de Recomendação e, assim, foi utilizado na caixa "itens vistos recentementee recomendações selecionadas". Uma inter-ligação foi estabelecida, dessa maneira, entre todos os itens visualizados, apresentando, em um primeiro momento, os produtos relacionados à última busca realizada (Figura 5).

Além disso, os Sistemas de Recomendação oferecem informações adjacentes à escolha de itens realizada pelo usuário. Pode-se observar que são exibidas muitas informações para auxiliar o usuário em sua experiência de compra, oferecendo pistas as quais podem levá-lo a descobrir uma necessidade oculta que precisa ser satisfeita. 


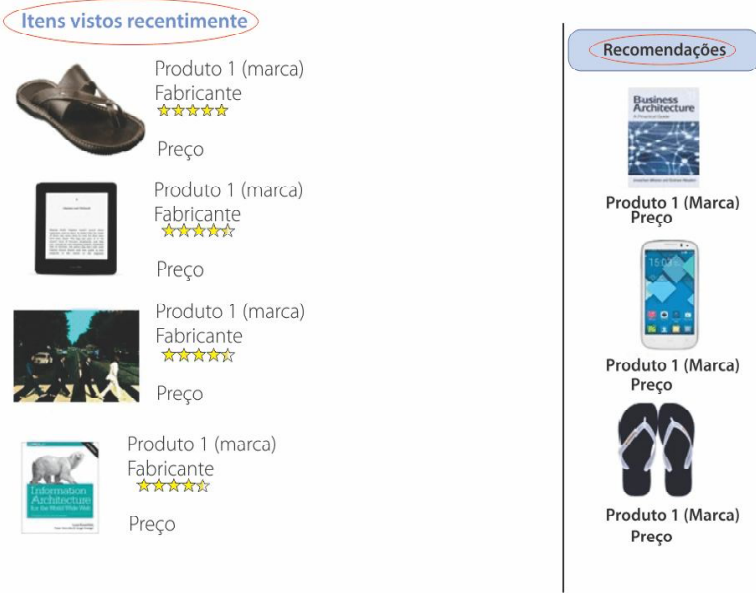

Figura 5. Histórico de navegação e de compras dos usuários utilizado para gerar recomendações.

Fonte: Elaborada pelos autores (2014).

\section{Sistema de Recomendação sob o ângulo de visão das Ciências da Informação}

Desde meados do século XX o desenvolvimento alcançado pela ciência na área da informação e da comunicação, produto dos avanços nas áreas da informática, eletrônica, telecomunicações, tecnologias de satélites, entre outras, representou um enorme avanço na evolução da sociedade. Essa realidade influenciou diretamente o dia a dia das pessoas, transformando sua maneira de conviver, trabalhar e interagir entre si.

Diante desse cenário, onde novos avanços tecnológicos são apresentados todos os dias, grandes acúmulos de informação são gerados e os usuários estão cada vez mais exigentes e seletivos com relação à informação que consomem a Ciência da Informação e seus especialistas lutam incansavelmente pela busca e criação de técnicas, sistemas, ferramentas e meios que facilitem o acesso à informação que essas pessoas precisam, no momento exato e com a qualidade que esperam. Um elemento derivado desse contexto é a criação de ambientes informacionais cada vez mais complexos, onde a interação entre sistemas com diferentes funções faz-se necessária para alcançar o objetivo principal: facilitar o acesso à informação.

No caminho para alcançar esse objetivo, as instituições de informação têm grandes desafios pela frente, eé por isso que, neste trabalho, sugere-se como proposta a inclusão dos Sistemas de Recomendação nos ambientes informacionais dessas organizações com a intenção de satisfazer as necessidades de dados dos usuários. Dessa forma, busca-se facilitar, também, o acesso a informações das quais o usuário não tinha conhecimento e que presumivelmente, possam ser importantes para ele. Esse fato converte os Sistemas de Recomendação em uma ferramenta que complementa os resultados obtidos nos processos de busca pelos usuários.

Dessa maneira, a utilização de Sistemas de Recomendação nos sistemas de informação das instituições de informação permitiria:

1) Apresentar recomendações que se encaixassem com os interesses declarados ou não pelo usuário, como "pesquisadores que tem alguma relação com sua linha de pesquisa e a possibilidade de contatá-los", "quantas publicações existem a respeito do tema pesquisado" e "quais são as mais citadas";

2) Gerar recomendações baseando-se no cruzamento das consultas feitas por outros usuários com o mesmo perfil e, assim, apresentar dados sobre os documentos mais consultados, mostrando uma hierarquização dos resultados baseada na quantidade de vezes que o item foi consultado; apresentar recomendações de aqueles documentos que o usuário não recebeu nos resultado da suas buscas, mas que, baseado no histórico de busca de outros usuários com perfis semelhantes, seriam apresentados, a partir de associações, aqueles itens que poderiam ter algum valor para a pesquisa do usuário e que este só perceberia depois de muita indagação, fato que diminuiria o tempo dedicado ao encontro de determinadas informações;

3) Oferecer recomendações sobre os documentos mais bem avaliados pelos colegas de pesquisa, tendo acesso aos comentários elaborados pelos pesquisadores, facilitando, assim, a decisão de consultar primeiro aqueles documentos que especialistas com o mesmo perfil e interesses de pesquisa avaliaram como mais importantes ou valiosos a partir de uma perspectiva científica.

A implantação dos Sistemas de Recomendação nas organizações de informação ampliaria as possibilidades de novas descobertas por parte dos usuários durante suas experiências de busca nos diferentes sis- 
temas da organização de informação. Permitiria, também, a apresentação de informações adjacentes para apoiar o encontro da informação que satisfaça as necessidades do usuário, tanto conhecidas, quanto desconhecidas, convertendo os Sistemas de Recomendação em mais uma ferramenta da qual os especialistas da informação poderiam fazer uso para cumprir a função de mediação entre o usuário e a informação.

\section{Conclusão}

Com a quantidade de informação disponível na web e levando-se em consideração que os processos de encontrabilidade da informação são cada vez mais complicados, muitos especialistas sugerem investir na melhoria e no aprimoramento dos projetos de Arquitetura da Informação na criação de ambientes informacionais. Para a melhora dos ambientes informacionais digitais, os sistemas de organização, rotulagem, navegação e busca dos websites devem estar focalizados nos desejos e nas necessidades informacionais de seus usuário e, assim, projetar esse ambiente de acordo com o seu público-alvo.

\section{Referências}

Amdahl, G. M.; Blaauw, G. A.; Brooks Jr., F. P. Architecture of the IBM System/360. IBM Journal for Research and Development, v.8, n.2, 1964. Available from: <http://www.research.ibm.com/ journal/rd/082/ibmrd0802C.pdf>. Cited: Dec. 15, 2014.

Batley, S. Information architecture for information professionals. Burlington: Elsevier Science, 2007.

Belvin, N.J. Croft, W.B. Information filtering and information retrieval: Two sides of the same coin? Communications of the ACM, v.35, n.12, p.29-45, 1992.

Brook, F.P. Architectural Philosophy. In: Buchholz, W. et al. (Ed.). Computer system: Project stretch. NewYork: McGraw-Hill Book, 1962. p.5-16.

Brown, P. Information architecture with XML: A management strategy. Chichester: Wiley; 2003.

Cook, M.A. Building enterprise information architectures: Reengineering information systems. Kent, OH: Prentice Hall, 1996.

Dijk, P. van. Information architecture for designers: Structuring web sites for business success. Brighton, UK: Rotovision, 2003.

Iskold, A. The art, science and business of recommendation engines. California: Readwrite, Jan. 16, 2007. Available from: <http://www.readwrite.com/2007/01/16/recommendation_ engines >. Cited: Dec. 18, 2014.
Os sistemas de recomendações colaboram com a estrutura organizacional do site, fornecendo uma melhor experiência ao usuário na interação com o sistema, sendo uma ferramenta que promove a encontrabilidade das informações/documentos. Cada conteúdo gerado por Sistemas de Recomendação é um meio de ofertar dados e itens do usuário, gerando novos eventos e propiciando novas descobertas.

A Arquitetura da Informação precisa considerar todos esses movimentos para atender a premissa de gerar uma melhor experiência aos usuários em diferentes ambientes informacionais. Os Sistemas de Recomendação são ferramentas tecnológicas as quais podem complementar projetos de Arquitetura da Informação e, assim, entregar informações aos usuários que possibilitem o processo de Encontrabilidade da Informação.

\section{Colaboradores}

E.B. Alvarez contribuiu na concepção, desenho do estudo, análise de dados e redação final. A.L.R. Siriani, S.A.B.G. Vidotti e A.M.G. Carvalho contribuíram na análise de dados.

Kahn, P.; Lenk, K. Website information architecture. Indianápolis: New Riders, 2001.

León, R.R. Arquitectura de información: análisis históricoconceptual. No Solo Usabilidad, n.7, 2008. Disponible em: $<$ http://nosolousabilidad.com/articulos/historia_arquitec tura_informacion.htm\#top_art.>. Acceso en: 15 dec. 2014.

Macedo, F.L.O. Arquitetura da informação: aspectos epistemológicos, científicos e práticos. 2005. Dissertação (Mestrado em Ciência da Informação) - Departamento de Ciência da Informação e Documentação, Universidade de Brasília, Brasília, 2005.

McCool, M. Information architecture in the Sonoran Biosphere. Tese (Ph. D. Information Science), New Mexico State University, Las Cruces, 2007. Available from: <http://www.tandfonline. com/doi/pdf/10.1080/03615261003622999>. Cited: Dec.18, 2014.

Morville, P. Ambient findability. Sebastopol: O'Really, 2005.

Morville, P.; Sullenger, P. Ambient findability: Libraries, serials, and the internet of things. The Serials Librarian, v.58, n.1-4, p.33-38, 2010.

Nielsen, J. Designing websites with authority: Secrets of an information architecture. Indianápolis: New Riders, 1998. 
Pake, G. E. Research at Xerox PARC: A founder's assessment. New York: IEEE Spectrum, 1985.

Reategui, E.B.; Cazella, S.C. Sistemas de recomendação. In: Congresso da Sociedade Brasileira de Computação, 25., 2005, São Leopoldo. A universalidade da computação: um agente inovação e conhecimento. São Leopoldo: Unisinos, 2005. p.306-348. Disponível em: <http://citeseerx.ist.psu.edu/ viewdoc/download?doi=10.1.1.92.2811\&rep=rep1\& type $=p d f>$. Acesso em: 10 dez. 2014

Resmini, A.; Rosati, L. Pervasive information architecture: Designing cross-channel user experiences. Burlington: Elsevier Science, 2011.

Resnick, P.; Varian, H.R. Recommender systems. Communications of the ACM, v.40, n.3, p.55-58, 1997.

Rosenfeld, L.; Morville, P. Information architecture for the World Wide Web. Sebastopol: O'Really, 1998.

Rosenfeld, L.; Morville, P. Information architecture for the World Wide Web. 3.ed. Sebastopol: O'Really, 2006.

Silva, P.M.; Dias, G.A. A arquitetura da informação centrada no usuário: estudo do website da Biblioteca Virtual em Saúde (BVS). In: Encontros Bibli: Revista Electrônica de Biblioteconomia e Ciência da Informação, v.13, n.26, p.119-130, 2008. Disponível: <http://www.periodicos.ufsc.br/index.php/eb/article/view/ 7200/6647>. Acesso em: 15 dez. 2014

Souza, G.M. Tags: o DNA dos sistemas de recomendação. 2012. Disponível em: <http://www.ecommercebrasil.com.br/ artigos/tags-o-dna-dos-sistemas-de-recomendacao/>. Acesso em: 18 dez. 2014.

Spagnolo, L.; Bolchini, D.; Paolini, P.; DI Blas, N. Beyond findability: Search-enhanced information architecture for content-intensive Rich Internet applications. Journal of Information Architecture, v.2, n.1, p.19-36, 2010. Available from: <http://journalofia.org/volume2/issue1/03-spagnolo/>. Cited: Dec. 19, 2014.

Straioto, F. A arquitetura da informação para a World Wide Web: um estudo exploratório. 2002. Dissertação (Mestrado em Ciência da Informação) - Faculdade de Filosofia e Ciências, Universidade Estadual Paulista, Marília, 2002.

Vechiato, F.L. Encontrabilidade da informação: contributo para uma conceituação no campo da Ciência da Informação. 2013. Tese (Doutorado em Ciência da Informação) - Faculdade de Filosofia e Ciências, Universidade Estadual Paulista, Marília, 2013.

Vechiato, F.L.; Vidotti, S.A.B.G. Subsídios teórico-metodológicos para a construção de ambientes informacionais digitais. In: Borges, M.M.; Casado, E.S. (Org.). A Ciência da Informação criadora de conhecimento. v.2. Coimbra: Imprensa da Universidade de Coimbra, 2009. p.287-299. Disponível em: <http://www.eventosiuc.com/ocs/public/conferences/1/ schedConfs/1/actas_EDIBCIC2009_2.pdf>. Acesso em: 15 de dez. 2014.

Vidotti, S.A.B.G.; Cusin, C.A.; Corradi, J.A.M. Acessibilidade digital sob o prisma da arquitetura da informação. In: Guimarães, J.A.C.; Fujita, M.S.L. (Org.). Ensino e pesquisa em Biblioteconomia no Brasil: a emergência de um novo olhar. São Paulo: Cultura Acadêmica, 2008. p.173-184.

Wodtke, C.; Govella, A. Information architecture: Blueprints for the web. 2.ed. Indianapolis: New Riders, 2009.

Wurman, R. Information architects. Zurich: Graphis Press Corp, 1996. 